\section{Junior biologists score partial victory over lab conditions}

\section{Alison Abbott, Munich}

For a group of junior biology researchers in Germany, proof has arrived that there is indeed strength in numbers.

In a final bid to get their voices heard, the group last spring submitted a joint complaint about their alleged mistreatment in a lab at the University of Konstanz. An internal investigation by the university has now supported some of their grievances.

The committee charged with investigating the researchers' claims finished its report on 24 May. It found that the lab's head, evolutionary biologist Axel Meyer, worked his team too hard, and that "occasionally insufficient" support "led to frustration or overtaxing" of the lab's junior members.

The committee's report stresses that the junior researchers made no accusations of data manipulation. But it states that some of the complaints hinted at scientific misconduct. The report, which was leaked to media outlets by one of the complainants, adds that Meyer's management style "could be detrimental" to the scientific activity of his group.

Observers of the intensely hierarchical German university system say that the case is probably the first time that junior scientists have successfully joined together to make a complaint against a professor.

Meyer, who joined the university in 1997, denies all charges of inappropriate behaviour. He says that incidents in the laboratory have been "blown out of proportion" in the report.

Meyer's busy and productive lab usually hosts about a dozen $\mathrm{PhD}$ students or postdocs from around the world. Some who passed through the lab say that they found the atmosphere scientifically stimulating; but others were unhappy and many of them left before the end of their contracts.

Finding little success in bringing individual complaints to the university, 16 researchers - all but six of whom have now left Konstanz - grouped together and presented a joint complaint in May 2003. In September the university asked its standing committee on responsibility in science to look into the case. The panel is chaired by law professor Dieter Lorenz and investigates scientific practice under guidelines set by the DFG, Germany's main research funding body.

The committee, which called on the advice of outside experts in Meyer's field, considered only a sample of the complaints filed. It concluded that Meyer had been insufficiently concerned about the welfare of e young scientists in his lab. In one extreme case, the report says, the nervous breakdown of a foreign PhD student "could be seen as an indicator of the general negative situation which developed from the optimization of scientific output".

A number of specific accusations were selected by the committee for investigation, and it decided that misconduct had occurred in four cases. These included advertising positions for which independence of research was promised but not delivered, and for which there was no specific budget. In a statement made through his lawyer, Meyer said that his assistants had "comparable freedom with non-tenure track US assistant professors".

The committee supported the students' allegations that Meyer also demanded honorary authorship on papers and that in one case he used "almost word for word" a grant proposal designed and written by a foreign scientist to the European Commission's Marie Curie postdoc programme for an application to another granting body. The young scientist involved claims that she arrived at the lab to find another student working on the project, and that she then had to work on something different. Meyer counters that he was deeply involved in developing the idea with her from the outset.

The panel found no evidence for bad practice in five other allegations it investigated. The young scientists say that they are pleased the committee has accepted some of their complaints, but that they still stand by the rejected claims.

Supporters of Meyer have rallied to his defence. "It was not an easy time, but it was the most interesting time in my life," Miguel Vences, now at the Zoological Museum in Amsterdam, says of his time in Meyer's lab. "Before then, I was not used to thinking so big."

The university declined to comment on how the case will now be taken forward. Its rector, Gerhart von Graevenitz, is expected to decide shortly what action should be taken.
Academics seek to cast peer review as a public service

Declan Butler, Paris

Scientists have been rapped on the knuckles by a panel of academics who spent more than a year assessing public awareness of peer review.

The panel's report, published on 24 June, says that researchers and their institutions should explain the importance of peer review to the public to help them to weigh up scientific claims. Every time scientific results are presented in public, it should be made clear which parts of the claims have been peer reviewed and which have not, the academics say.

"A culture of explaining and asking about peer review all along the line from radio phone-ins to ministerial briefings - will put a lot more pressure on people to explain exactly what the status of the work is," says Tracey Brown, director of the London-based watchdog Sense About Science, which produced the report.

The Sense about Science panel included Colin Blakemore, head of the UK Medical Research Council; Peter Lachmann, an immunologist at the University of Cambridge; and John Maddox, former editor of Nature.

Their report lists a litany of scares that had their origin in publicized but unpublished claims, including the health risks of radiation from mobile phones, the fear that the MMR (measles, mumps and rubella) vaccine could cause autism, and that acrylamide in fried foods could cause cancer. Such scares could be killed at birth if journalists and politicians paid more attention to the publication status of the original claims, says Brown.

That's an ambitious goal. A poll commissioned this year by the Science Media Centre and Nature - conducted by the London-based market-research company MORI - showed that almost $75 \%$ of the public don't know what peer review is. Sense About Science will work with research and educational bodies to encourage teaching about peer review in schools and universities, says Brown.

But scientists themselves are the report's main target. Researchers often whine about the hassles of peer review, complaining about the practicalities and potential flaws of the system, says Brown. Instead, she says, scientists should use peer review to explain to the public the validity of scientific claims. "Here is something in scientists' armoury to help the public understand science better, but they never think about peer review apart from moaning about it," says Brown. 